\title{
Clinical and microbiological aspects of the use of Lactobacillus rhamnosus PL1strains in proctological patients with symptoms of chronic proctitis
}

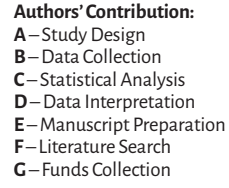

G-Literature Search
G-Funds Collection

Article history: Received: 31.10.2016 Accepted:10.01.2017 Published:30.06.2017

ABSTRACT Recurrent proctitis and the symptoms associated therewith pose significant clinical problem in proctological patients.

The objective of this study was to assess the impact of the probiotic Lactobacillus rhamnosus PL1 strain on the clinical presentation and composition of intestinal microbiota in patients with symptoms of proctitis in the course of hemorrhoidal disease and diverticulosis.

Material consisted of 24 patients in whom no complete clinical improvement could be obtained after the treatment of the underlying disease. Subject to the assessment was the presence and the intensity of clinical symptoms as well as qualitative and quantitative changes in the composition of bacterial flora detected in the stool before, during and after a 9 -week supplementation with the probiotic Lactobacillus rhamnosus PL1 strain.

Results: In the entire study group, the intensity of pain after 12 weeks was significantly lower $(p=0.011)$ compared to baseline; the intensity of flatulence and abdominal discomfort was reduced significantly as early as after 3 weeks, with the difference reaching a highly significant level after 12 weeks $(P<0.0001)$. No significant difference was observed in the frequency of the reported episodes of diarrhea, constipation, as well as itching and burning in the anal region. As early as after 3 weeks of supplementation with the probiotic L. rhamnosus PL1 strain, significant qualitative and quantitative changes were observed in the composition of intestinal microbiota; the changes differed depending on the underlying disease. An increase in the total counts of the bacteria of Lactobacillus genus, particularly L. rhamnosus PL1 strain was observed regardless of the underlying disease.

Conclusion: the probiotic Lactobacillus rhamnosus PL1 strain appears to be useful in restoring appropriate ratios of bacterial populations in patients presenting with symptoms of proctitis in the course of the treatment of certain diseases of the lower gastrointestinal tract.

KEYWORDS: $\quad$ hemorrhoidal disease, diverticulosis, probiotics, gut microbiota, Lactobacillus rhamnosus PL1

\section{INTRODUCTION}

In proctological practice one may encounter a significant number of patients who suffer from recurrent proctitis and symptoms associated therewith despite having undergone the frequently successful treatment for the underlying disease of the lower gastrointestinal tract (hemorrhoidal disease, anal fissure, perianal fistula, diverticulosis). Patients presenting with symptoms of moderately intense inflammation in anoscopic examination and lack of other abnormalities in laboratory, endoscopic and imaging studies main complain of pain within the lower abdomen and the anal region, abdominal discomfort, flatulence, constipation, sudden bowel movements, feeling of incomplete voiding as well as itching and burning in the anal region. The change in nutritional habits and the use of elimination diets are insufficient to bring about the expected results. The possibility that the symptoms may be due to the disturbance in composition of gut microbiota is usually considered as the last option. Even so, physicians are reluctant in prescribing probiotics as they assume that supplementation with a single bacterial strain, sometimes of dubious activity, is insufficient to dramatically change the composition of gut microbiota and consequently the clinical presentation of the disease.

Appropriate ratios of bacterial populations within the gut microbiota have long been known to be a condition required for the proper function of the large intestine and the entire immune system. The compo- sition of gut microbiota is determined by numerous factors such as the age (1), nutritional habits, chronic diseases, or the need for treatment using antibiotics or steroidal anti-inflammatory drugs. Significant shifts in the ecological equilibrium of intestinal microflora may also occur over short time due to the inflammatory processes within the intestinal lumen involving the release of reactive oxygen species (ROS) and inflammatory mediators or bleeding within the intestinal tract. The disturbance of this sensitive microbial equilibrium results in the maintenance of inflammation within the large intestinal mucosa and consequently to the increase in clinical symptoms.

Every year provides new scientific evidence to support the claim that dysbiosis, i.e. disturbed composition of gut microbiota plays an important role in the pathogenesis or is a consequence of both intestinal (inflammatory bowel disease, irritable bowel syndrome, diverticulosis, celiac disease) as well as extraintestinal (allergies, asthma, metabolic syndrome, cardiovascular diseases) systemic disorders (2) and cancers.

Appreciating the value of the proper composition of gut microflora, the authors made an attempt at verification whether and how supplementation using a single probiotic bacterial strain affected the clinical presentation of the disease and the gut microbiota composition in proctological patients presenting with symptoms of proctitis. 
The objective of this study was to assess the impact of the probiotic Lactobacillus rhamnosus PL1 strain on the clinical presentation and composition of intestinal microbiota in patients with symptoms of proctitis in the course of hemorrhoidal disease and diverticulosis.

\section{MATERIAL AND METHOD}

\section{Patients}

Included in the analysis were a total of 24 patients, including 17 patients with hemorrhoidal disease and 7 patients with diverticulosis treated at the Outpatient Clinic of the Department of General, Oncological and Gastrointestinal Surgery with no complete clinical improvement following the treatment of the underlying disease. Qualified for the study were:

- Patients with grade II and III hemorrhoidal disease after conservative and/or surgical treatment and presenting with symptoms of rectal mucositis in anoscopic examination, with the history of earlier standardized, 8-week conservative treatment (ointments and suppositories), improvement in follow-up anoscopic examination, and persisting complaints; and

- Patients with endoscopically confirmed diverticulosis, currently without features of acute diverticulitis, who had completed the standard treatment with rifaximin for 6 months ( $2 \times 2$ tablets for 7 days repeated every 1 month) and nonetheless presented with persistent features of proctitis in anoscopic examination and symptoms within the lower gastrointestinal tract.

All patients were included in the study after at least 4 weeks of washout with regard to all antibiotic medications or probiotic products.

The observation time in this prospective, self-controlled study was 12 weeks. Baseline evaluations included the presence and intensity of clinical symptoms, proctological examination (with anoscopic assessment), laboratory analyses (hematology, CRP), and standardized collection of a stool sample (SS1) from the rectal ampulla for determination of baseline gut microbiotic status. The presence of clinical symptoms of gas and stool incontinence was assessed by means of Wexner scale. Following the baseline assessments, each patient received the probiotic product containing the single Lactobacillus rhamnosus PL1 strain for regular use 1 time daily for 9 weeks. The presence (assessed as 0 or 1) and the changes in the intensity of clinical symptoms (assessed on the scale from 0 to 5) was recorded throughout the study in the patient diary. Follow-up visits were held during the observation period, including V2 after 3 weeks, V3 after 6 weeks, and V4 after 12 weeks from the start of probiotic treatment. Stool samples were collected for microbiological analyses during the first visit (SS1) as well as during the second visit (SS2) i.e. after 3 weeks of probiotic treatment. The microbiological analyses of the stool sample were quantitative determinations focusing on the changes in the counts of bacterial strains comprising the gut microbiota and on the efficacy of gut colonization by the probiotic L. rhamnosus PL1 strain. In addition, the presence and changes in the intensity of clinical symptoms were assessed at V3 (after 6 weeks) and V4 (after 12 weeks).

\section{Microbiological analysis of stool samples}

Stool samples were collected from each patient at visits V1 and V2. Stool was collected from rectal ampulla about $7 \mathrm{~cm}$ above the sphincter muscles using an anoscope. Following collection, samples were immersed in Schaedler broth with the addition of $15 \%$ of glycerol in sterile $50 \mathrm{~mL}$ tubes and immediately frozen at $-20^{\circ} \mathrm{C}$. The material was transported to the microbiological lab in dry ice for deep freezing. Before culturing, the samples were thawed at room temperature and blended using a stomacher (Bagmixer $400 \mathrm{P}$, Bionovo). The material was inoculated in $100 \mu \mathrm{L}$ aliquots onto appropriate solid growth media, including McConkey agar for Gram-negative bacilli, Columbia agar for and streptococci and staphylococci, Schaedler agar for anaerobic bacteria, and MRS for lactic acid bacteria of genus Lactobacillus. Sabourand agar was used for confirming the presence of Candida fungi in the study material. The inoculated material was placed in a heater set at $37^{\circ} \mathrm{C}$ in aerobic or anaerobic conditions for 24 or 48 hours, respectively. The cultured colonies were identified in terms of genus and species using bioMerieux API kits (API 20E, API 20A, API Strep, API Staph, API 50CH) and subsequently quantified. Final results were expressed as culture forming units per one gram of stool (CFU/g of stool). Only in the case of lactic acid bacteria preliminarily identified using the phenotyping method (API $50 \mathrm{CHL}$ ) as L. rhamnosus, further identification was performed using a genotyping method, namely PCR with species-specific primers (PrI: CAG ACT GAA AGT CTG ACG G, RhaII: GCG ATG CGA ATT TCT ATT ATT ) (3). Pulsed-field gel electrophoresis (PFGE) was used in order to decisively confirm the colonization of gastrointestinal tracts of the study patients with the probiotic L. rhamnosus PL1 strain. The technique allows to compare the genomic DNA profiles of all bacteria identified as $L$. rhamnosus to the reference profile typical for the PL1 strain. Isolation of genomic DNA and selection of restriction enzymes was based on the methodology proposed by Tynkkynen (4).

\section{Statistical analysis}

The collected results were processed and entered into excel spreadsheets (raw data). The raw data were subjected to statistical analysis (Student's t-test, chi-square test and Mann-Whitney's U-test; the latter two tests were used as non-parametric tests to estimate the errors of measurement) to demonstrate the changes between the baseline and the end of study (endpoint analysis) as well as between the baseline and follow-up visits (interim analysis). Primary endpoints were defined as the presence (assessed as 0 or 1 ) and the changes in the intensity of clinical symptoms (assessed on the scale from 0 to 5) Secondary endpoints were defined as qualitative and quantitative changes in the composition of bacterial species present in stool samples, including the bacteria of the family Enterobacteriaceae, bacilli of Escherichia coli, enterococci and Enterococcus faecalis strains. Changes in the quantitative ratios between the counts of aerobic bacteria and strictly anaerobic bacteria were also analyzed. Additional attention was paid to the quantitative changes observed between stool samples collected at visits V1 and V2 with reference to the total count of Lactobacillus genus, particularly of the probiotic $L$. rhamnosus PL1 strain.

\section{RESULTS}

The study group of 24 patients ( 13 women and 11 men) included 17 patients with hemorrhoidal disease and 7 patient with diver- 


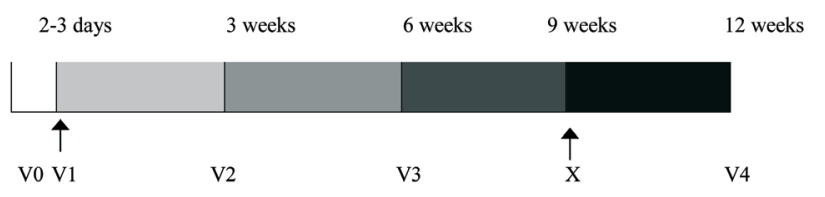

V0 - the screening visit; V1 - patient inclusion, V2, V3 - follow-up visits, V4 - study end visit, $\mathrm{X}$ - end of probiotic product treatment

Fig. 1. Study design

ticulosis. The mean age of patients was 51.7 years. The characteristics of both groups is provided in Table 1.

Changes in the intensity of the clinical symptoms were observed in the course of the study after 3,6 , and 12 weeks. The intensity of pain after 12 weeks was significantly lower $(p=0.011)$ as compared to baseline. The intensity of flatulence decreased significantly after 3 weeks; in a longer observation period (12 weeks), the difference reached a highly significant level $(\mathrm{p}=0.0002)$. Abdominal discomfort was reduced starting from the early observation stage (significant difference achieved as early as after 3 weeks),reaching a highly significant level $(\mathrm{p}<0.0001)$ after 12 weeks. See Table 2 for details. Baseline itching and burning in the anal region was reported by $33.3 \%$ as compared to $12.5 \%$ after 12 weeks; the difference, however, was not statistically significant $(\mathrm{p}=0.49)$. Identical results were obtained for diarrhea (33.3\% before vs. $12.5 \%$ after 12 weeks from the start of the treatment, $\mathrm{p}=0.49$ ). Baseline constipation was reported by $58.33 \%$ $(14 / 24)$ of patients; after 3 weeks, the percentage dropped to $12.5 \%$ $(3 / 24)$ and after 12 weeks from the start of the treatment (3 weeks after discontinuation of the probiotic product) the problem was not reported by any of the patients $(\mathrm{p}<0.0001)$.

In a detailed analysis of the group of 17 patients with hemorrhoidal disease, particular differences were observed in the intensity of flatulence $(p=0.005)$ and abdominal discomfort $(p=0,002)$ which were significantly reduced. The difference in the intensity of sudden bowel movements was not statistically significant (Table 3). No significant difference was observed in the reported rates of diarrhea $(6 / 17$ vs. $2 / 17, p=0.556)$, constipation $(5 / 17$ vs. $0 / 17$, $\mathrm{p}=0.097)$, as well as itching and burning in the anal region $(6 / 17$ vs. $3 / 17, \mathrm{p}=0.789$ ).

In the group of patients with diverticulosis, the most evident changes included the reduction in the intensity of pain $(p=0.025)$, flatulence $(\mathrm{p}=0.029)$ and abdominal discomfort $(\mathrm{p}=0.005)$ after 12 weeks (Table 4). No differences were observed with regard to the rates of itching in the anal region, diarrhea $(2 / 7 \mathrm{vs} .1 / 7, \mathrm{p}=0.836)$ and constipation ( $2 / 7$ vs. $0 / 7, \mathrm{p}=0.056)$.

\section{Results of microbiological analyses}

Three weeks of oral supplementation using a single probiotic strain L. rhamnosus PL1 resulted in significant changes in the composition of gut microbiota. A significant reduction in the population of aerobic bacteria $(\mathrm{p}<0.0001)$ was observed in patients with hemorrhoidal disease while the strictly anaerobic bacterial counts remained unchanged (Figure 2A). The aforementioned drop (observed at the second visit) was associated with the statistically significant reduction in the counts of Gram-negative bacilli of the family En-
Tab. I. Characteristics of the study groups

\begin{tabular}{|c|c|c|c|}
\hline & $\begin{array}{l}\text { PATIENTS WITH } \\
\text { HEMORRHOIDAL } \\
\text { DISEASE }\end{array}$ & $\begin{array}{l}\text { PATIENTS WITH } \\
\text { DIVERTICULOSIS }\end{array}$ & $\begin{array}{l}\text { TOTAL NUMBER OF STUDY } \\
\text { PATIENTS }\end{array}$ \\
\hline$N$ & 17 & 7 & 24 \\
\hline Women & $41.2 \%(7)$ & $85.7 \%$ (6) & $54.2 \%(13)$ \\
\hline Men & $58.8 \%(10)$ & $14.3 \%(1)$ & $45.8 \%(11)$ \\
\hline
\end{tabular}

\begin{tabular}{llll} 
Mean age & 43.5 & 70.4 & 51.7 \\
$\begin{array}{l}\text { Duration of } \\
\text { symptoms } \\
\text { (months) }\end{array}$ & 36.5 & 28.7 & 34.2 \\
$\begin{array}{l}\text { Conservative } \\
\text { treatment }\end{array}$ & $100 \%(17 / 17)$ & $100 \%(7 / 7)$ & $100 \%(24 / 24)$ \\
$\begin{array}{l}\text { Surgical } \\
\text { treatment }\end{array}$ & $70.6 \%(12 / 17)$ & $14.3 \%(1 / 7)$ & $54.2 \%(13 / 24)$ \\
\hline $\begin{array}{l}\text { Wexner scale } \\
\text { score }\end{array}$ & 0.5 & 2 & 0.96 \\
\hline CRP & 4.07 & 6.9 & 4.88
\end{tabular}

Tab. II. Intensity of clinical symptoms within the study group at individual time points $($ mean \pm SEM)

\begin{tabular}{lllll|} 
& V1 & V2 & V4 & P \\
\hline Abdominal pain & $1.78 \pm 0.28$ & $1.33 \pm 0.27$ & $0.58 \pm 0.19$ & 0.01 \\
\hline $\begin{array}{llll}\text { Flatulence } \\
\text { Abdominal }\end{array}$ & $2.69 \pm 0.27$ & $1.47 \pm 0.29$ & $1.0 \pm 0.22$ & 0.0002 \\
$\begin{array}{l}\text { discomfort } \\
\begin{array}{l}\text { Sudden bowel } \\
\text { movements }\end{array}\end{array}$ & $2.00 \pm 0.31$ & $1.47 \pm 0.23$ & $0.76 \pm 0.25$ & $<0.0001$ \\
\hline
\end{tabular}

Tab. III. Intensity of clinical symptoms in patients with hemorrhoidal disease (mean \pm SEM)

\begin{tabular}{lllll} 
& V1 & V2 & V4 & P \\
\hline Abdominal pain & $1.56 \pm 0.36$ & $1.46 \pm 0.35$ & $0.45 \pm 0.24$ & 0.074 \\
Flatulence & $2.81 \pm 0.35$ & $1.6 \pm 0.38$ & $1.00 \pm 0.33$ & 0.005 \\
$\begin{array}{l}\text { Abdominal } \\
\text { discomfort }\end{array}$ & $2.62 \pm 0.41$ & $1.4 \pm 0.32$ & $0.63 \pm 0.33$ & 0.002 \\
$\begin{array}{l}\text { Sudden bowel } \\
\text { movements }\end{array}$ & $2.56 \pm 0.48$ & $1.53 \pm 0.49$ & $0.81 \pm 0.48$ & 0.059 \\
\hline
\end{tabular}

terobacteriaceae $(\mathrm{p}<0.0001)$, including E. coli $(\mathrm{p}<0,0001)$, and cocci of genus Enterococcus ( $\mathrm{p}<0.0001)$, (Figure 3A).

In patients with diverticulosis, the quantitative ratio between aerobic and anaerobic bacterial counts differed significantly from those observed in patients with hemorrhoidal disease. After 3 weeks of supplementation, a significant increase in the total aerobic bacterial counts was observed ( $\mathrm{p}=0.0001$ ) (Figure $2 \mathrm{~B}$ ). This increase was due to the increase in the population of Gram-negative bacilli of genus Enterobacteriaceae ( $\mathrm{p}=0.0001)$ but not to the increase in the population of cocci of the family Enterococcus, since the latter, also classified as aerobic bacteria, showed a decreasing trend at V2 ( $\mathrm{p}=0.0001)$ (Figure 3B). 
The reduction in the total population of fecal cocci of the family Enterococcus as observed at the second visit (V2) may be directly associated with the improvement of clinical parameters observed as early as after 3 weeks of probiotic treatment (Table 4).

No bacteria of genus Lactobacillus were found in the baseline stool sample (SS1) in 7 out of 17 patients (41.18\%) treated for hemorrhoidal disease. After 3 weeks of oral supplementation, bacteria of this genus were found in 15 out of 17 patients $(88.24 \%)$ (Table 5). Colonization by L. rhamnosus PL1 strain was confirmed in 15 out of 17 patients treated for hemorrhoidal disease which amounts to colonization efficacy rate of $88.24 \%$ (Figure 4 ).

In case of patients treated for diverticulosis, colonization of the gastrointestinal tract with the L.rhamnosus PL1 strain after 3 weeks of supplementation was confirmed in 4 cases ( $57 \%$ of patients). With regard to the impact of the L. rhamnosus PL1 strain on the increase on the total counts of the bacteria of genus Lactobacillus, it was even more evident than in patients with hemorrhoidal disease (Table 6). Namely, only 1 in 7 patients included in the study presented with Lactobacillus colonization at V1 (14\%) while the number of patients with Lactobacillus colonization at V2 increased to 6 out of 7 patients (86\%).

\section{DISCUSSION}

Improvement in the intensity of clinical symptoms was observed in the during the study in the entire patient population. After 9 weeks of supplementation using a single probiotic Lactobacillus rhamnosus PL1 strain, a statistically significant decrease was observed in the frequency of pain, flatulence, abdominal discomfort and constipation as reported by patients. The change in clinical presentation was dependent on the underlying disease. In patients treated for hemorrhoidal disease, the improvement was observed mainly in the intensity of flatulence and abdominal discomfort. Despite the lack of statistical significance, improvement was observed in some patients with regard to the intensity of sudden bowel movements and diarrhea (4 out of 6 patients who reported the problem at baseline), constipation (all 5 patients who reported the problem at baseline), as well as itching and burning in the anal region (3 out of 6 patients who reported the problem at baseline). The few available literature reports on the subject confirm our observations. In a prospective, randomized study conducted in women with hemorrhoidal disease and constipation following natural childbirth, supplementation with a probiotic Lactobacillus casei strain afforded a significant improvement with regard to both abdominal and anal region symptoms compared to the placebo group (5). Two meta-analyses $(6,7)$ assessing the impact of probiotics on the functional constipation revealed their efficacy in regulating intestinal passage, frequency of defecation and stool consistency. However, the obtained effect depended on the probiotic strain being used in the study (Bifidobacterium lactis, Lactobacillus casei Shirota, Escherichia coli Nissle 1917, L. casei rhamnosus Lcr35, L. rhamnosus GG). In this study, also the Lactobacillus rhamnosus PL1 strain was shown to belong to the class of probiotics demonstrating efficacy in relieving the abdominal symptoms. The lack of significance in the frequency of constipation was probably due to the small number of subject in the study group.

Despite the small number of subjects, significant improvement was observed in the group of patients treated for diverticulosis with regard to the intensity of constipation as well as abdominal discom-
Tab.IV. Intensity of clinical symptoms in patients with diverticulosis (mean \pm SEM)

\begin{tabular}{|c|c|c|c|c|}
\hline & V1 & V2 & $V_{4}$ & $\mathbf{P}$ \\
\hline Abdominal pain & $2.28 \pm 0.42$ & $1.00 \pm 0.36$ & $0.83 \pm 0.04$ & 0.024 \\
\hline Flatulence & $2.42 \pm 0.42$ & $1.17 \pm 0.4$ & $1.00 \pm 0.25$ & 0.029 \\
\hline $\begin{array}{l}\text { Abdominal } \\
\text { discomfort }\end{array}$ & $2.85 \pm 0.4$ & $1.66 \pm 0.21$ & $1.00 \pm 0.36$ & 0.005 \\
\hline $\begin{array}{l}\text { Sudden bowel } \\
\text { movements }\end{array}$ & 2 & 0 & 0 & - \\
\hline
\end{tabular}

Tab.V. Populations of the bacteria of genus Lactobacillus isolated from the stool samples collected from patients treated for hemorrhoidal disease.

\begin{tabular}{|c|c|c|c|c|}
\hline \multirow[t]{2}{*}{ No. } & V1 & V2 & & \\
\hline & $\begin{array}{l}\text { TOTAL COUNT OF } \\
\text { LACTOBACILLUS } \\
\text { STRAINS (CFU/C OF } \\
\text { STOOL) }\end{array}$ & $\begin{array}{l}\text { INCLUDING THE } \\
\text { TOTAL COUNT OF } \\
\text { LACTOBACILLUS } \\
\text { RHAMNOSUS PL' } \\
\text { STRAIN (CFU/G OF } \\
\text { STOOL) }\end{array}$ & $\begin{array}{l}\text { TOTAL COUNT OF } \\
\text { LACTOBACILLUS } \\
\text { STRAINS (CFU/C } \\
\text { OF STOOL) }\end{array}$ & $\begin{array}{l}\text { INCLUDING } \\
\text { THE TOTAL } \\
\text { COUNT OF } \\
\text { LACTOBACILLUS } \\
\text { RHAMNOSUS } \\
\text { PL' }^{\prime} \\
\text { STRAIN (CFU/C } \\
\text { OF STOOL) }\end{array}$ \\
\hline 1. & $1.1 \times 106$ & 0 & $9.3 \times 104$ & 0 \\
\hline 2. & $2.0 \times 105$ & 0 & $3.8 \times 106$ & $6.3 \times 103$ \\
\hline 3. & $1.5 \times 106$ & 0 & $9.5 \times 106$ & $7.1 \times 106$ \\
\hline 4. & 0 & 0 & $4.8 \times 107$ & $4.8 \times 107$ \\
\hline 5. & $1.9 \times 104$ & 0 & $5.6 \times 105$ & $3.5 \times 104$ \\
\hline 6. & $9.7 \times 105$ & 0 & $1.4 \times 106$ & $2.0 \times 105$ \\
\hline 7. & 0 & 0 & $6.5 \times 105$ & $6.5 \times 105$ \\
\hline 8. & $1.3 \times 108$ & 0 & $9.5 \times 104$ & $4.7 \times 102$ \\
\hline 9. & $2.8 \times 103$ & 0 & $4.4 \times 106$ & $4.4 \times 106$ \\
\hline 10. & $1.2 \times 104$ & 0 & $1.1 \times 106$ & $1.1 \times 106$ \\
\hline 11. & $2.3 \times 106$ & 0 & $6.3 \times 102$ & $6.3 \times 102$ \\
\hline 12. & 0 & 0 & $9.1 \times 105$ & $9.1 \times 105$ \\
\hline 13. & 0 & 0 & $1.4 \times 104$ & $1.4 \times 104$ \\
\hline 14. & $8.1 \times 106$ & 0 & $1.3 \times 105$ & $1.3 \times 105$ \\
\hline 15. & 0 & 0 & 0 & 0 \\
\hline 16. & 0 & 0 & $7.7 \times 105$ & $7.7 \times 105$ \\
\hline 17. & 0 & 0 & $3.4 \times 106$ & $6.7 \times 104$ \\
\hline
\end{tabular}

Tab. VI. Populations of the bacteria of genus Lactobacillus isolated from the stool samples collected from patients treated for diverticulosis.

\begin{tabular}{|lllll|}
\hline NO. & V1 & V2 & & \\
TOTALCOUNT OF & $\begin{array}{l}\text { INCLUDING THE } \\
\text { STRAINS (CFU/G OF } \\
\text { STOOL) }\end{array}$ & $\begin{array}{l}\text { TOTAL COUNT OF } \\
\text { LACTOBACILLUS } \\
\text { RHAMNOSUS PL1 } \\
\text { STRAIN (CFU/G OF } \\
\text { STOOL) }\end{array}$ & $\begin{array}{l}\text { LACTOBACILLUS } \\
\text { STRAINS (CFU/G } \\
\text { OF STOOL) }\end{array}$ & $\begin{array}{l}\text { INCLUDING THE } \\
\text { TOTAL COUNT OF } \\
\text { LACTOBACILLUS } \\
\text { RHAMNOSUS PL1 } \\
\text { STRAIN (CFU/G OF } \\
\text { STOOL) }\end{array}$ \\
\hline 1. & $5.9 \times 107$ & 0 & $1.1 \times 104$ & $7.3 \times 103$ \\
\hline 2. & 0 & 0 & $2.0 \times 102$ & $2.0 \times 102$ \\
\hline 3. & 0 & 0 & $6.0 \times 106$ & $6.0 \times 105$ \\
\hline 4. & 0 & 0 & $1.2 \times 104$ & 0 \\
\hline 5. & 0 & 0 & $6.1 \times 105$ & $6.1 \times 105$ \\
\hline 6. & 0 & 0 & 0 & 0 \\
\hline 7. & 0 & 0 & $6.78 \times 105$ & 0 \\
\hline
\end{tabular}

fort and pain. This was not surprising considering the underlying disease. Disturbed composition of gut microbiota is considered to be the key factor responsible for exacerbations in the course 

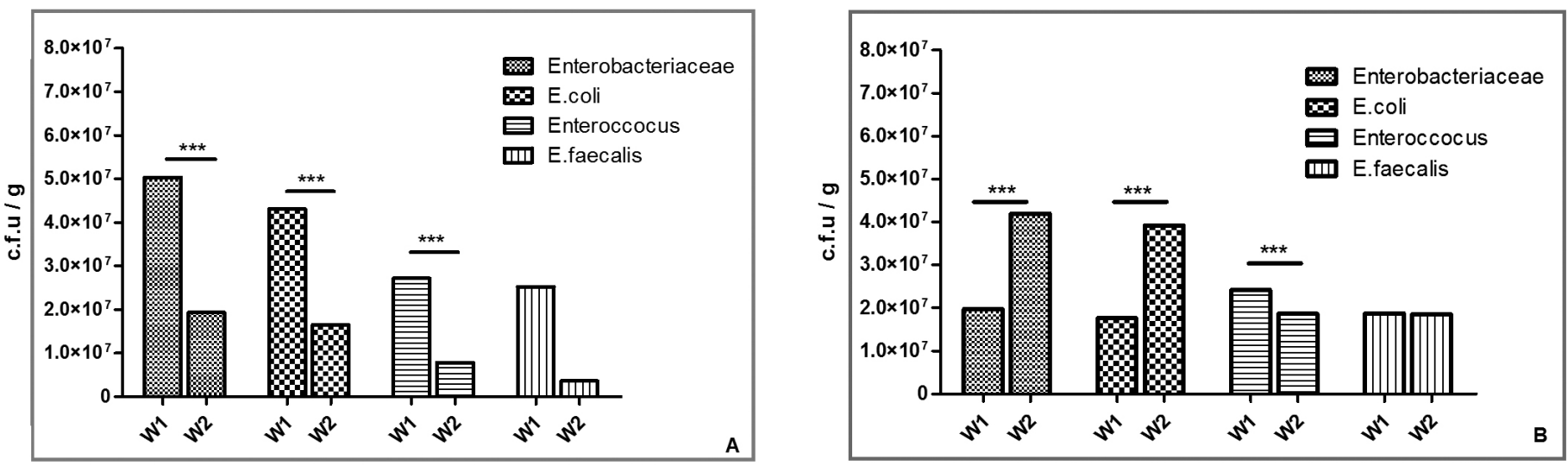

Fig. 2. Total counts of aerobic and anaeroobic bacteria in gut microbiota before $\left(V_{1}\right)$ and during $\left(V_{2}\right)$ supplementation with the probiotic $L$. rhamnosus $P$ L1 strain: $\left.A\right)$ in patients treated for hemorrhoidal disease; and B) in patients treated for diverticulosis.
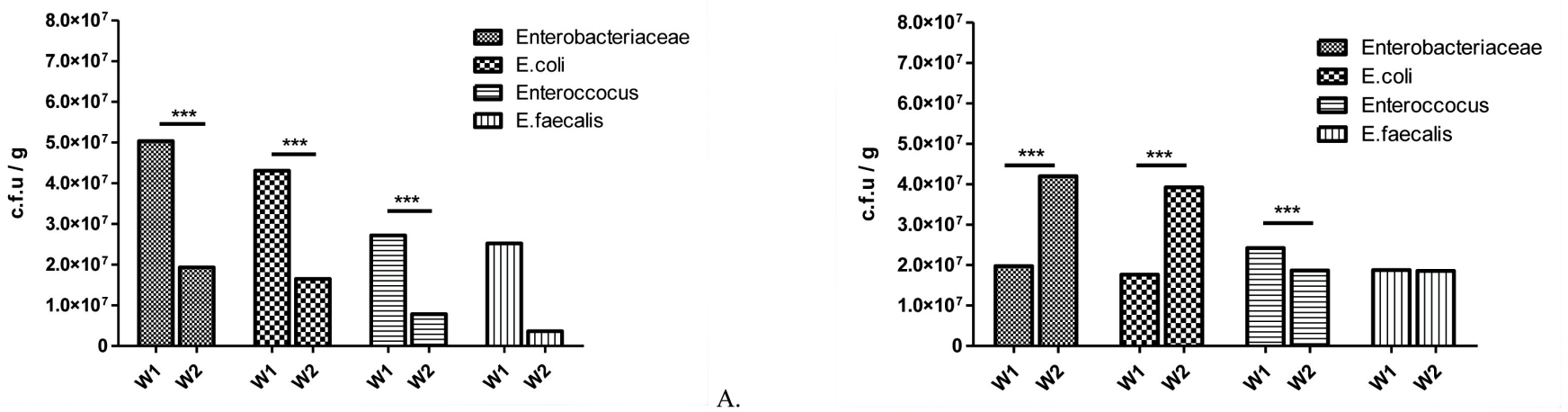

Fig. 3. The mean population of the bacteria of geni Enterobacteriaceae (including E. coli) and Enterococcus (including E. faecalis) for: A) patients treated for hemorrhoidal disease; and B) patients treated for diverticulosis.

of diverticulosis. This makes probiotics an efficient component of the treatment of acute diverticulitis (8). Probiotics also play an important role in preventing the recurrence of the disease as well as in reducing the intensity of abdominal symptoms in patients with uncomplicated diverticulosis (10). In the study by Lamiki et al., probiotic strains of Lactobacillus acidophilus, L. heveticus, Bifidobacterium spp. 420, and Lactobacillus paracasei significantly reduced abdominal symptoms in more than $70 \%$ of subjects. The analysis of stool samples collected from these patients revealed a statistically significant increase in the number of Lactobacilli and Bifidobacteriae during the supplementation period, and the genomic analysis confirmed the survival of the supplemented strains throughout the 6 month study period.

Microbiological analysis performed by the authors revealed significant changes in the composition of gut microbiota as early as 3 weeks after the start of supplementation using a single probiotic strain Lactobacillus rhamnosus PL1. The changes varied depending on the underlying disease and disturbances caused by that disease in the bacterial composition of intestinal microflora.

In the course of hemorrhoidal disease, occasional occurrence of blood in the rectal lumen is sufficient to disturb the microbiotic composition of the distal segment of the large intestine. Changes caused by the presence of blood may persist for long periods, even after successful treatment of the underlying disease. The increase in concentration of free ions of iron released upon decomposition of hemoglobin leads to an increase in the counts of Gram-negative bacteria of the family Enterobacteriaceae, particularly the bacilli of E. coli originating from the natural intestinal microflora (11). The persistence of the inflammation within the lower rectum and anus is due to the increase in the population of E. coli bacteria rather than to their special virulence (12). Such an increase in the E. coli counts was observed in most patients with hemorrhoidal disease in the baseline examination (SS1).

In case of patients treated for diverticulosis, a correlation was observed between the improvement in clinical parameters and the significant drop in the population of cocci of genus Enterococcus. It is known from the literature that Enterococcus faecalis may, to an extent similar to that of $E$. coli, induce the production of pro-inflammatory cytokines such as TNF $\alpha$ or IL-12p70 (13). Moreover, due to its peptidoglycan-containing cellular wall, Enterococcus faecalis is capable of initiating activation of TLR2-dependent nuclear factor $\mathrm{kB}$ within the immune cells, thus stimulating the immune system and consequently inducing inflammation. Thus, one may assume that the increased counts of E. faecalis within the intestinal lumen and walls in the course of advanced inflammation contribute to the persistence of this process (14).

Extension of the standard treatment by additional supplementation using a probiotic product containing the Lactobacillus rhamnosus 
PL1 strain significantly improved the clinical parameters of patients with the hemorrhoidal disease as well as patients with diverticulosis.

The effect exerted by Lactobacillus on colonocytes may be manifold, but it consists mainly in stimulation of mucus production, thus improving the function of the intestinal barrier (15). The integrity of the intestinal barrier may be improved by Lactobacillus strains also by means of increasing the mucosal levels of $\beta$-defen$\sin 2$ (16). In addition, bacteria of genus Lactobacillus were shown to be capable of inhibiting cytokine-induced apoptosis of intestinal wall cells (17). One may also assume that the bacteria of genus Lactobacillus, thanks to their synthesis of numerous antibacterial agents such as bacteriocins, lactic acid, acetic acid of pyroglutamic acid may actively reduce the populations of Gram-negative bacilli as observed in patients with hemorrhoidal disease as early as after 3 weeks of supplementation.

In patients with diverticulosis, a decrease in the counts of cocci of genus Enterococcus was observed with simultaneous increase in the number of patients successfully colonized with the bacteria of genus Lactobacillus which may be indicative of the higher

\section{REFERENCES}

1. Duncan S.H., Flint H.J. Probiotics and prebiotics and health in ageing populations. Maturitas, 2013; 75(1): 44-50

2. Carding S., Verbeke K., Vipond D.T. i wsp. Dysbiosis of the gut microbiota in disease. Microb. Ecol. Health Dis., 2015; 26: 26191

3. Walter J., Tannock G.W., Tilsala-Timisjarvi A. i wsp. Detection and identification of gastrointestinal Lactobacillus species by using denaturing gradient gel electrophoresis and species-specific PCR primers. Appl. Environ. Microbiol., 2000; 66(1): 297-303

4. Tynkkynen S., Satokari R., Saarela M. i wsp. Comparison of ribotyping, randomly amplified polymorphic DNA analysis, and pulsed-field gel electrophoresis in typing of Lactobacillus rhamnosus and L. casei strains. Appl. Environ. Microbiol., 1999; 65(9): 3908-3914

5. Sakai T., Kubota H., Gawad A., i wsp. K. Effect of fermented milk containing Lactobacillus casei strain Shirota on constipation-related symptoms and haemorrhoids in women during puerperium. Benef. Microbes, 2015; 6(3): 253-262

6. Dimidi E., Christodoulides S., Fragkos K.C. i wsp. The effect of probiotics on functional constipation in adults: a systematic review and meta-analysis of randomized controlled trials. Am. J. Clin. Nutr., 2014; 100(4): 1075-1084

7. Chmielewska A., Szajewska H. Systematic review of randomised controlled trials: probiotics for functional constipation. World J. Gastroenterol., 2010; 16(1): 69-75

8. Narula N., Marshall J.K. Role of probiotics in management of diverticular disease. J. Gastroenterol. Hepatol., 2010; 25(12): 1827-1830 efficacy of L. rhamnosus PL1 in the competition for receptors located on the intestinal epithelial surface as compared to the cocci of genus Enterococcus.

As early as after 3 weeks of probiotic supplementation, a two-fold increase in intestinal colonization with the bacteria of genus Lactobacillus was observed in patients with hemorrhoidal disease as well as in the patients with diverticulosis. This effect is of particular value in the patient groups included in the study since the probiotic bacteria are directly responsible for the maintenance of correct microbial equilibrium within the gastrointestinal lumen. By reducing the $\mathrm{pH}$ of the intestinal lumen with their metabolites, they improve gastrointestinal motility and reduce the intensity of constipations.

To conclude, the probiotic strain appears to be useful in restoring appropriate ratios of bacterial populations in patients presenting with symptoms of proctitis in the course of the treatment of certain diseases of the lower gastrointestinal tract. However, further studies conducted in larger patient populations are required to dispel all doubts that may remain due to limited character of this study.

9. Dughera L., Serra A.M., Battaglia E. i wsp. Acute recurrent diverticulitis is prevented by oral administration of a polybacterial lysate suspension. Minerva Gastroenterol. Dietol., 2004; 50(2): 149-153

10. Lamiki P., Tsuchiya J., Pathak S., Okura R. i wsp. Probiotics in diverticular disease of the colon: an open label study. J. Gastrointestin Liver Dis., 2010; 19(1):31-36

11. Griffiths E. The iron uptake systems of pathogenic bacteria. W: Bullen J.J., Griffiths E.: Iron and infection. John Willey, Chichester 1985

12. Pilarczyk-Żurek M., Chmielarczyk A., Gosiewski T. i wsp. Possible role of Escherichia coli in propagation and perpetuation of chronic inflammation in ulcerative colitis. BMC Gastroenterol, 2013; 13: 61

13. Marcinkiewicz J., Ciszek M., Bobek M. i wsp. Differential inflammatory mediator response in vitro from murine macrophages to lactobacilli and pathogenic intestinal bacteria. Int. J. Exp. Pathol., 2007; 88(3): 155-164

14. Golińska E., Tomusiak A., Gosiewski T. i wsp. Virulence factors of Enterococcus strains isolated from patients with inflammatory bowel disease. World J Gastroenterol, 2013; 19(23): 3562-3572

15. Mack D.R., Michail S., Wei S . i wsp. Probiotics inhibit enteropathogenic E. coli adherence in vitro by inducing intestinal mucin gene expression. Am. J. Physiol., 1999; 276(4): G941-950

16. Fellermann K., Wehkamp J., Herrlinger K.R. i wsp. Crohn's disease: a defensin deficiency syndrome? Eur. J. Gastroenterol. Hepatol., 2003; 15(6): 627-634

17. Yan F., Polk D.B. Probiotic bacterium prevents cytokine-induced apoptosis in intestinal epithelial cells. J. Biol. Chem., 2002; 277(52): 50959-50965 


\begin{tabular}{llll}
\hline Word count: $3700 \quad$ Page count: 7 & Tables: $6 \quad$ Figures: $4 \quad$ References: 17
\end{tabular}

DOI: $\quad 10.5604 / 01.3001 .0010 .1083$

Table of content: http://ppch.pl/resources/html/articlesList?issueld=9993

Copyright: Copyright @ 2017 Fundacja Polski Przegląd Chirurgiczny. Published by Index Copernicus Sp. z o. o. All rights reserved.

Competing interests: The authors declare that they have no competing interests.

2 The content of the journal "Polish Journal of Surgery" is circulated on the basis

- of the Open Access which means free and limitless access to scientific data.

(c) (i) This material is available under the Creative Commons - Attribution 4.0 GB. The full terms of this license are available on: cc)

Corresponding author: Katarzyna Borycka-Kiciak, M.D., Ph.D; Orlowski Hospital, Medical Centre of Postgraduate Education, Department of General, Oncological and Gastrointestinal Surgery; 231 Czerniakowska Street, 00-416 Warsaw, Poland; tel. +48 2262900 04, +48 502733 961, fax. +48 2262278 33; e-mail: kborycka@interia.pl

Cite this article as: Borycka-Kiciak K., Strus M., Pietrzak P., Kiciak A., Wawiernia K., Mikołajczyk D., Gałęcka M., Heczko P., Tarnowski W.; Clinical and microbiological aspects of the use of Lactobacillus rhamnosus PL1 strains in proctological patients with symptoms of chronic proctitis; Pol Przegl Chir 2017: 89 (32): 16-22 